\title{
Surgical treatment of bilateral temporalis and masseteric hypertrophy: Report of a case
}

\author{
Eduardo Varela Parente ${ }^{1}$, Marcelo Galindo Silvares ${ }^{1 *}$, Mateus Malheiros Naegele ${ }^{2}$, \\ Danilo Passeado Branco Ribeiro ${ }^{1}$, Mauricio Andrade ${ }^{1}$ \\ ${ }^{1}$ Oral and Maxillofacial Surgery Division of Pedro Ernesto University Hospital, State University of Rio de Janeiro, Rio de Janeiro, Brasil \\ ${ }^{2}$ Fluminense Feaderal University, Niterói, Brasil \\ Email: "marcelogalindos@gmail.com
}

Received 30 January 2013; revised 5 March 2013; accepted 13 March 2013

\begin{abstract}
Hypertrophy of the masticatory muscles is characterized by generalized enlargement of the muscular tissue that affects the facial esthetic and may or not be accompanied by pain [1-3]. This condition can be congenital, but more often it is acquired. The origin has been attributed to muscle hyperactivity and parafunctionsoriginated from stressful lifestyle that causes bruxing or clenching [2,3]. Masseteric muscle hypertrophy is a relative common clinical entity that can affect one or both sides and is also thought to causesecondary enlargement of the mandibular angle as a result of functional remodeling. Temporalis muscle hypertrophy is a rare clinical entity and only a few cases are reported. More often, it presents a bilateral involvement and is usually associated with masseteric hypertrophy [3]. The aim of this report is to present a case of bilateral temporalis and masseteric muscles hypertrophy treated surgically.
\end{abstract}

Keywords: Bilateral Temporalis

\section{REPORT OF A CASE}

A 18-year-old male was referred to the Oral and Maxillofacial Surgery Department of the State University of Rio de Janeiro for evaluation of bilateral swelling in his temporal and mandibular region. The patient had been aware of the swelling for many years and complained about his facial appearance.

The clinical evaluation showed a marked bilateral swelling involving the temporalis and masseter muscles (Figures 1-3). The bulksgrow to be more prominent during the clenching and the palpation reveals a soft mass at rest and a rigid mass during contraction (Figure 4). There was no pain during palpation or function. The mandibular angles showed significant enlargementre-

"Corresponding author. sulting in square-jaw appearance. No bruxism, clenching or further parafunctional habit was identified and there were no relevant findings at medical history.

Computed tomography showed a homogeneous enlargement of both masseter and temporal muscles (Figures 5). Panoramic radiograph showed marked enlargement of both mandibular angles (Figure 6).

Treatment was carried out by bilateral resection of the deep portion of the temporalis muscle through coronal approach and surgical recontouring of the mandibular angles with an oscillatory saw through intra-oral approach (Figures 7-9). Caution must be taken to avoid excessive muscular removal at the anterior aspect of the temporal fossae because it could cause a depression in this area. The author's recommendation is to begin the resection by the posterior region and gradually progress anteriorly. Moreover, proper closure of the detached tissues is critical to produce optimal esthetic results. Suture resuspension of the temporalis fascia to the pericraniumis necessary once the temporalis muscle is detached.

Six months following the procedure, the patient-showed a harmonic facial appearance without evidence of depression, recurrence, dysfunction or asymmetry (Figures 10-14).

\section{DISCUSSION}

The bilateral hypertrophy of the masseter and temporalis muscles is a relative rare condition and its origin is widely discussed. It has previously been referred as the Minotaur Syndrome in some reports because of their harsh facial physiognomy. Bruxism, clenching, and gum chewing are feasible causes of masticatory muscle enlargement. Psychological factors, particularly emotional stress, anxiety, and personality disorders, has been also related to these muscular hyperactivity. Nevertheless, the etiology cannot always be verified [1-8]. In the case reported, we could not identify any parafunctional habit or psychosocial disturbance and for that reason, the muscle 


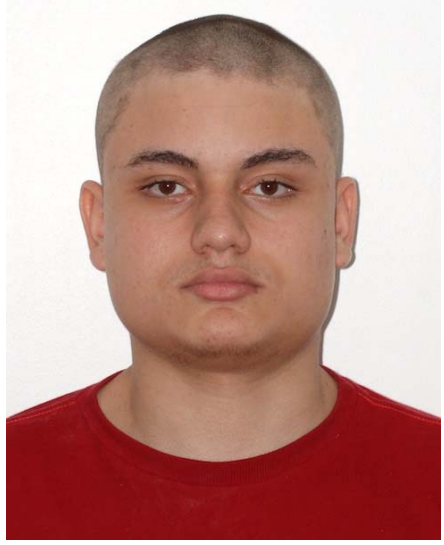

Figure 1. Preoperative frontal view.

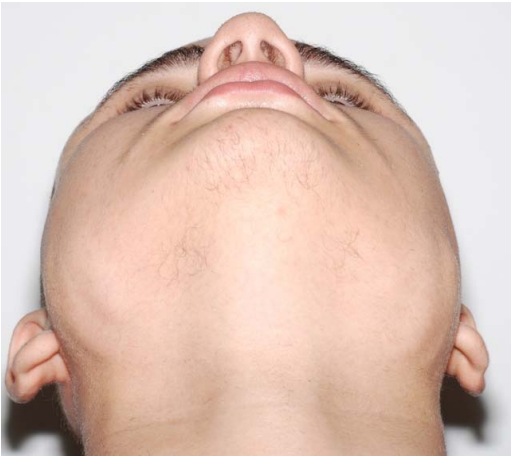

Figure 2. Preoperative submental vertical view.

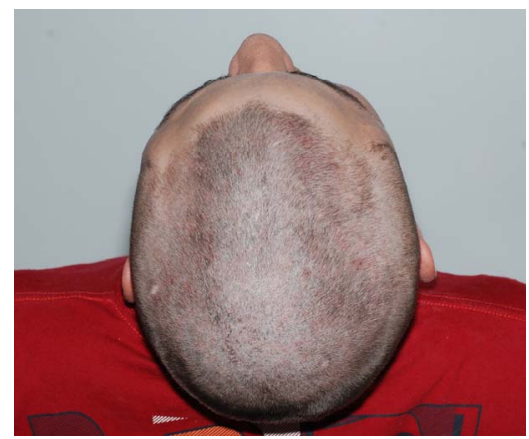

Figure 3. Preoperative supracranialview.

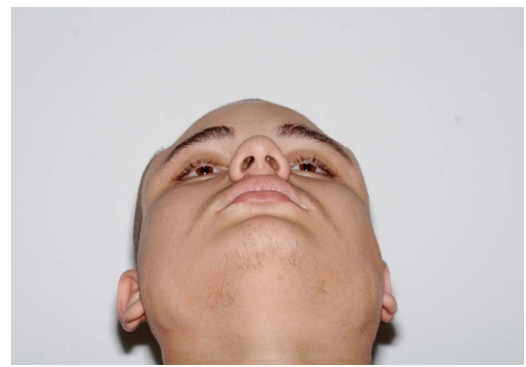

Figure 4. Preoperative submental oblique view of temporalis muscle bulk during contraction.

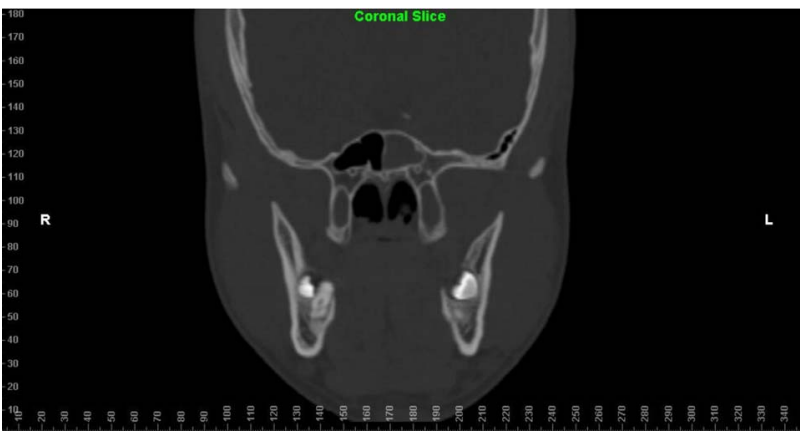

Figure 5. Preoperative computed tomography showing bilateral enlargement of temporalis muscle and masseteric muscle.

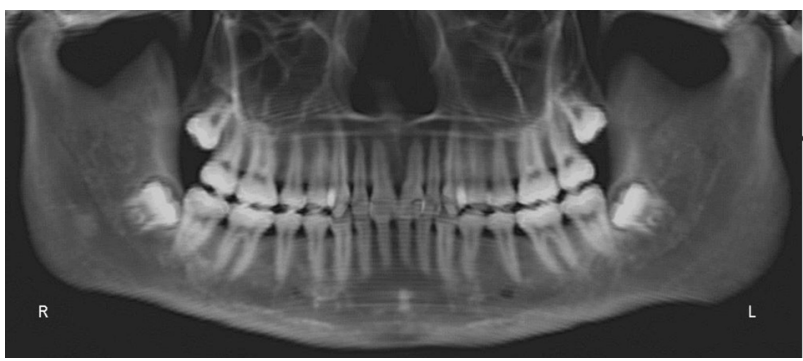

Figure 6. Preoperative panoramic radiograph.

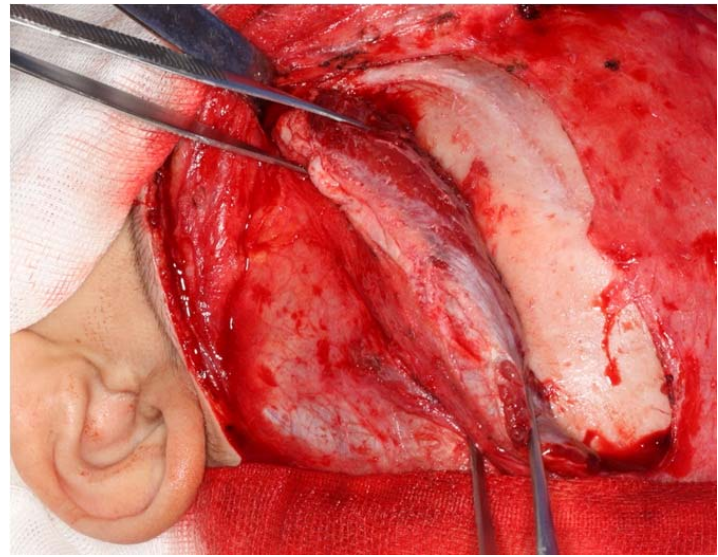

Figure 7. Transoperative view of temporalis hypertrophy.

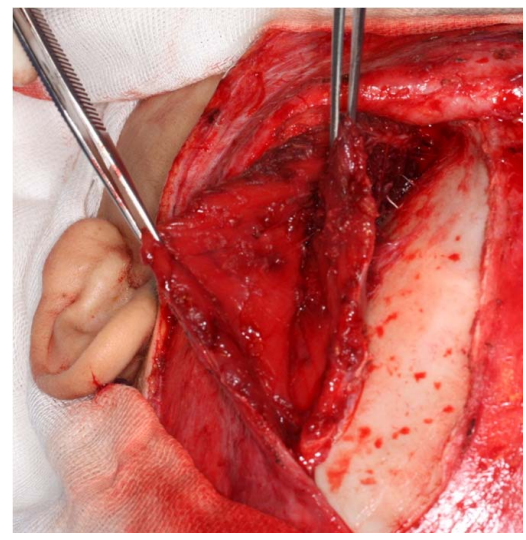

Figure 8. Resection of the deep portion of the temporalis muscle. 


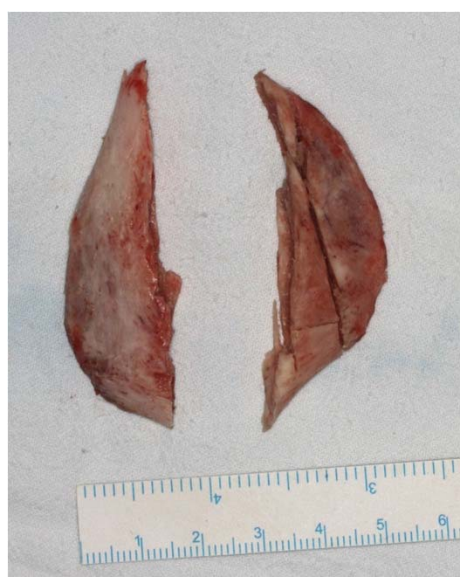

Figure 9. Symmetric removal of both mandibular angles.

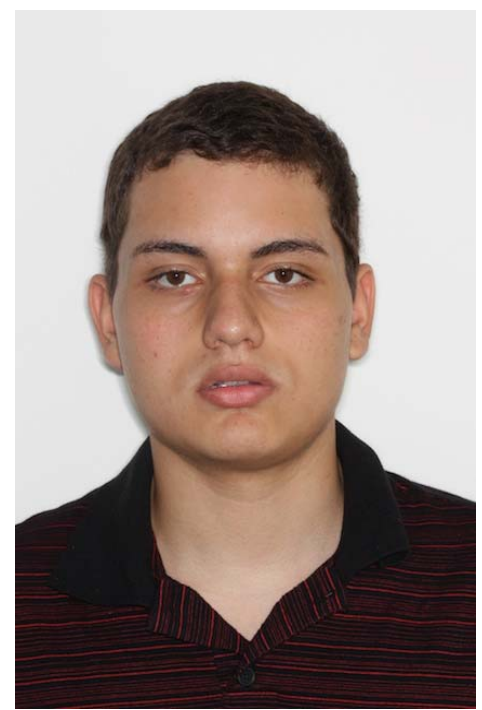

Figure 10. Postoperative frontal view.

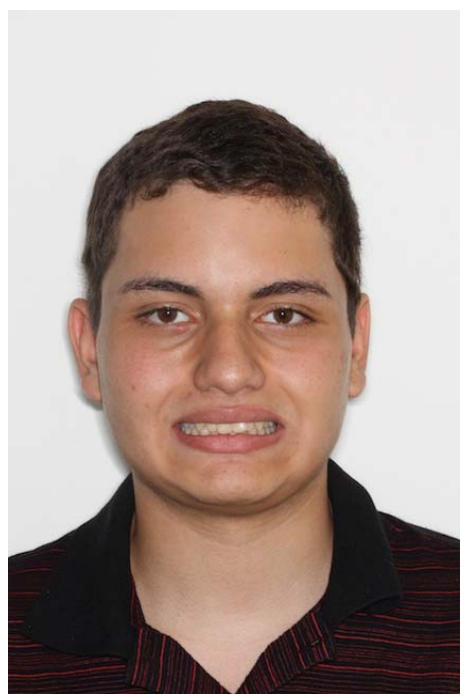

Figure 11. Postoperative frontal view during contraction.

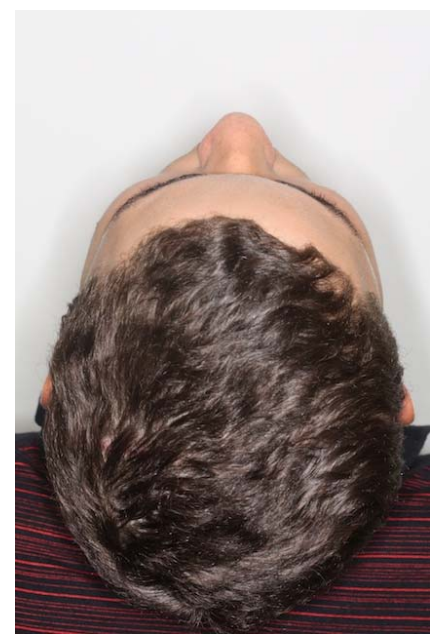

Figure 12. Postoperative supracranial view.

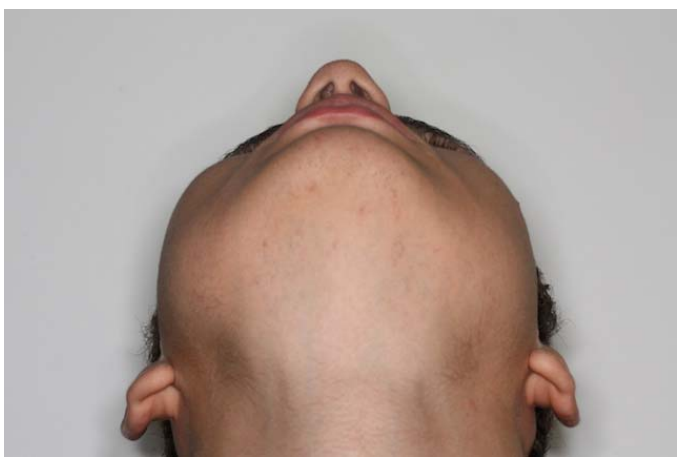

Figure 13. Postoperative submental vertical view.

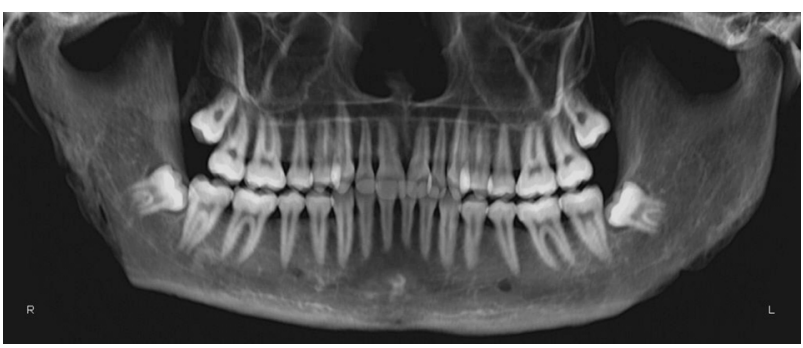

Figure 14. Postoperative panoramic radiograph.

hypertrophy may be regarded as idiopathic.

Traditionally, surgical procedures have beenthe treatment of choice for reduction of masticatory muscle hypertrophy $[4,9,10]$. The first surgical technique used to treat the masseteric hypertrophy was published in 1947 and consists in partial resection of the muscle bulk through extra-oral approach [9]. Later, additional bony removalat the mandibular angle was advocated [5]. Even though provides good access, the extra-oral approach produces an external scar and presents the risk of damage to the mandibular branch of the facial nerve $[5,9,11]$. By the time the intraoral approach was first described, in 1959, it was extremely difficult to remove bone at the 
mandibular angle due to the limited view [12]. With development of surgical saws, specific retractors (e.g. Bauer and Merrill-Lavasseur retractors), and the publication of new surgical techniques, the intraoral approach has become routine [11-14]. Intraoral removal of the mandibular angle without removing any parts of the masseter muscle has then become one of the most commonsurgical technique to treat the masseteric hypertrophy. The disadvantages of this surgical technique are the same presented by most oral surgical procedures performed under general anesthesia (i.e. postoperative haemorrhage, haematoma, edema, infection, anesthesia complications) [11,14].

Few case reports and technical notes of surgical treatment of the temporalis hypertrophy are available [1-3, 15,16]. Fractional resection of the muscle is the most common surgical technique indicated. Partial removal by a modified liposuction has been suggested [15]. The disadvantages of the surgical treatment include the need for coronal flap under general anesthesia and, sometimes, requirement of closed suction drains for 48 hours.

The botulinum toxin A has been used successfully to correct temporalis and masseteric hypertrophy [10]. It is an established drug for the treatment of a variety of neuromuscular disorders and its effect of paralysis and subsequent muscle atrophy has been beneficial to treat this condition [17]. However, these effects are temporary and, for that reason, hypertrophic muscles could regain their original size after few months $[10,17,18]$. It can be a non-invasive option to treatpatients with muscle hypertrophy, butthis therapy has showed a variable rate of recurrence and lack of long-term follow-up studies.

\section{REFERENCES}

[1] Legg, J.W. (1880) Enlargement of the temporal and masseter muscles on both sides. Trans Pathol Soc Lond, 31, 361-366.

[2] Von Lindern, J.J., Niederhagen, B., Appel, T., Berge, S. and Reich, R.H. (2001) Type A botulinum toxin for the treatment of hypertrophy of the masseter and temporal muscles: An alternative treatment. Plastic and Reconstructive Surgery, 107, 327-332. doi:10.1097/00006534-200102000-00004

[3] Kalish, G.H. and Gellis, S.S. (1971) Hypertrophy of the masseter or temporalis muscles or both. American Journal of Diseases of Children, 121, 346-347.

[4] Smyth, A.G. (1994) Botulinum toxin treatment of bilateral masseteric hypertrophy. British Journal of Oral and Maxillofacial Surgery, 32, 29-33. doi:10.1016/0266-4356(94)90169-4

[5] Adams, W.M. (1949) Bilateral hypertrophy of the masse- ter muscle: An operation for correction. British Journal of Plastic Surgery, 2, 78.

[6] Roncevic, R. (1986) Masseter muscle hypertrophy. Aetiology and therapy. Journal of Oral and Maxillofacial Surgery, 14, 344. doi:10.1016/S0301-0503(86)80322-8

[7] Balatasouras, D., Kaberos, A., Psaltakos, V., Papaliakos, E. and Economou, N. (2004) Bruxism: Two case reports. Acta Otorhinolital, 24, 165-170.

[8] Da Silva, K. and Mandel, L. (2006) Bilateral temporalismusclehypertrophy: A case report. Oral Surgery, Oral Medicine, Oral Pathology, Oral Radiology \& Endodontics, 102, 1-3. doi:10.1016/j.tripleo.2006.02.002

[9] Gurney, C.E. (1947) Chronic bilateral benign hypertrophy of the masseter muscles. American Journal of Surgery, 73, 137-139. doi:10.1016/0002-9610(47)90304-8

[10] Ali, K., Sittampalam, G. and Malik, M.A. (2010) Bilateral temporalishypertrophy. International Journal of Oral and Maxillofacial Surgery, 39, 292-307. doi:10.1016/j.ijom.2009.09.005

[11] Vasconcellos, R.J.H., de Oliveira, D.M., Vasconcelos, B.C.E. and Nogueira, R.V.B. (2005) Modified intraoral approach to removal of mandibular angle for correction of masseteric hypertrophy: A technical note. Journal of Oral and Maxillofacial Surgery, 63, 1057-1060. doi:10.1016/j.joms.2005.03.027

[12] Ginestet, G., Frezieres, H. and Merville, L. (1959) La correction chirurgica de l'hypertrophie du masseter. Annales De Chirurgie Plastique Esthetique, 4, 787.

[13] Beckers, H.L. (1977) Masseteric muscle hypertrophy and its intraoral surgical correction. Journal of Maxillofacial Surgery, 5, 28-35. doi:10.1016/S0301-0503(77)80072-6

[14] Nishida, M. and Iizuka, T. (1995) Intraoral removal of the enlarged mandibular angle associated with masseteric hypertrophy. Journal of Oral Maxillofacial Surgery, 53, 1476-1479.

[15] Morselli, P.G. (2000) Temporalis muscle hypertrophy: A new plastic surgery procedure. Plastic \& Reconstructive Surgery, 106, 1156-1161. doi:10.1097/00006534-200010000-00028

[16] Morselli, P.G. (1993) The minotaur syndrome: Plastic surgery of the facial skeleton. Aesthetic Plastic Surgery, 17, 99-102. doi:10.1007/BF02274728

[17] To, E.W., Ahuja, A.T., Ho, W.S., King, W.W., Wong, W.K., Pang, P.C. and Hui, A.C. (2001) A prospective study of the effect of botulinum toxin a on masseteric muscle hypertrophy with ultrasonographic and electromyographic measurement. British Journal of Plastic Surgery, 54, 197-200. doi:10.1054/bjps.2000.3526

[18] Bentsianov, B.L., Francis, A. and Blitzer A. (2004) Botulinum toxin treatment of temporomandibular disorders, masseteric hypertrophy, and cosmetic masseter reduction. Operative Techniques in Otolaryngology-Head and Neck Surgery, 15, 110-113. doi:10.1016/j.otot.2004.02.002 